\title{
Diabetes treatment patterns and goal achievement in primary diabetes care (DiaRegis) - study protocol and patient characteristics at baseline
}

Peter Bramlage ${ }^{1 \dagger}$, Christiane Binz ${ }^{2 \dagger}$, Anselm K Gitt $^{3}$, Michael Krekler ${ }^{2}$ Tanja Plate ${ }^{4}$, Evelin Deeg ${ }^{3}$, Diethelm Tschöpe 5* $^{*}$

\begin{abstract}
Background: Patients with type 2 diabetes are at an increased risk for disease and treatment related complications after the initial approach of oral mono/dual antidiabetic therapy has failed. Data from clinical practice with respect to this patient group are however scarce. Therefore we set up a registry in primary care documenting the course and outcomes of this patient group.

Methods: Diabetes Treatment Patterns and Goal Achievement in Primary Diabetes Care (DiaRegis) is a prospective, observational, German, multicenter registry including patients with type-2 diabetes in which oral mono/dual antidiabetic therapy has failed. Data were recorded at baseline and will be prospectively documented during visits at $6 \pm 1,12 \pm 2$ and $24 \pm 2$ months. The primary objective is to estimate the proportion of patients with at least 1 episode of severe hypoglycemia within one year.

Results: 313 primary care offices included 4,048 patients between June 2009 and March 2010 of which 3,810 patients fulfilled the in- and exclusion criteria. $46.7 \%$ of patients were female; patients had a median diabetes duration of 5.5 years and most were obese with respect to BMI or waist circumference. $\mathrm{Hb}^{\mathrm{Alc}}$ at baseline was $7.4 \%$, fasting plasma glucose $142 \mathrm{mg} / \mathrm{dl}$ and postprandial glucose $185 \mathrm{mg} / \mathrm{dl}$. Co-morbidity in this patient population was substantial with $17.9 \%$ having coronary artery disease, $14.4 \%$ peripheral neuropathy, $9.9 \%$ heart failure and $6.0 \%$ peripheral arterial disease. $68.6 \%$ of patients received oral monotherapy, $31.4 \%$ dual oral combination therapy. The most frequent antidiabetic agent used as monotherapy was metformin (79.0\%) followed by sulfonylureas (14.8\%).

Conclusions: DiaRegis is a large, prospective registry in primary diabetes care to document the course and outcomes of patients with type-2 diabetes in which the initial approach of oral mono/dual antidiabetic therapy has failed. The two year follow-up will allow for a prospective evaluation of these patients during multiple adjustments of therapy.
\end{abstract}

\section{Background}

Patients with type 2 diabetes are at an increased risk for disease and treatment related complications. This is particularly true at a point where patients are switched from oral monotherapy, to combination drug therapies,

\footnotetext{
* Correspondence: diethelm.tschoepe@ruhr-uni-bochum.de

† Contributed equally

${ }^{5}$ Herz- und Diabeteszentrum Nordrhein-Westfalen in Bad Oeynhausen,

Universitätsklinik der Ruhr Universität, Bochum, Germany

Full list of author information is available at the end of the article
}

diabetes is usually more advanced, complicated by a number of co-morbid disease conditions and the likelihood of disease and treatment related complications is increased. Intensive glucose control-in particular when complex insulin strategies are used-is associated with a 5 -fold increased risk for severe hypoglycemia, which could induce harm in some patients [1].

The recent guideline of the German Diabetes Society (Deutsche Diabetes Gesellschaft, DDG) recommends to 
combine metformin with a number of different oral antidiabetic drugs or a GLP-1 analogue in patients whose $\mathrm{Hb}_{\mathrm{A} 1 \mathrm{c}}$ remains $\geq 6.5 \%$ but is $<7.5 \%$ after $3-6$ month of metformin monotherapy treatment (with nutritional counselling and sports). Insulin should be added if $\mathrm{Hb}_{\mathrm{Alc}}$ is still $\geq 6.5 \%$ after 3-6 month treatment with combination therapy or if $\mathrm{Hb}_{\mathrm{Alc}}$ is $\geq 7.5 \%$ after the initial metformin/other OAD monotherapy [2].

Of particular importance when optimizing pharmacotherapy is the balance between optimal blood glucose adjustments $\left(\mathrm{Hb}_{\mathrm{A} 1 \mathrm{c}}\right.$, postprandial glucose) and the risk of hypoglycemia, the potential increase in body weight observed specifically with sulfonylureas, glinides and insulin regimens.

\section{$\mathrm{Hb}_{\mathrm{A1c}}$ adjustment}

The primary target of guideline recommended therapies is the adjustment of $\mathrm{Hb}_{\mathrm{Alc}}$ as the ultimate therapeutic goal. Guidelines use $\mathrm{Hb}_{\mathrm{A} 1 \mathrm{c}}$ as a surrogate in a lack of hard end points for most antidiabetic treatments [2]. This approach however is surprising since patients with type 2 diabetes whose $\mathrm{Hb}_{\mathrm{A} 1 \mathrm{c}}$ was reduced from 8 to $7 \%$ in the UKPDS (United Kingdom Prospective Diabetes Study) did not exhibit a reduction in cardiovascular events [3]. That $\mathrm{Hb}_{\mathrm{A} 1 \mathrm{c}}$ may only be an incomplete surrogate for cardiovascular endpoints was recently confirmed by the results of ACCORD (Action to Control Cardiovascular Risk in Diabetes, [4]), ADVANCE (Action in Diabetes and Vascular Disease: Preterax and Diamicron Modified Release Controlled Evaluation, [5]) and VADT (Veterans Affairs Diabetes Trial) [6]. It was found that intensive blood sugar lowering had no significant benefit in terms of decreasing cardiovascular risk. For new antidiabetic treatments the FDA issued guidelines requesting specific prospective analysis of the submitted data to assess cardiovascular safety and gives directions to the patient population to be entered in terms of cardiovascular comorbidity [7].

\section{Postprandial Glucose}

This rise and fall of postprandial glucose level is mediated by the first-phase insulin response, in which large amounts of endogenous insulin are released, usually within $10 \mathrm{~min}$, in response to nutrient intake. In individuals with type 2 diabetes, the first-phase insulin response is severely diminished or absent, resulting in persistently elevated postprandial glucose throughout most of the day [8]. Although there is still some debate whether postprandial glucose is a proper measure of overall glucose control, a number of studies have demonstrated a close correlation between postprandial glucose and glycaemic control [9-14]. Regardless of whether postprandial glucose is a better predictor of $\mathrm{Hb}_{\mathrm{Alc}}$ than fasting/preprandial glucose, most researchers agree that the best predictor of $\mathrm{Hb}_{\mathrm{A} 1 \mathrm{c}}$ is mean blood glucose, which is a composite of both fasting/preprandial and postprandial glucose. It is reasonable to assume, that achieving near-normal postprandial glucose levels without risk for hypoglycemia is essential to achieving overall glycaemic control.

\section{Hypoglycemia}

Patients with blood glucose values less than $2.22 \mathrm{mmol} / \mathrm{l}$ are regarded, irrespective of symptoms, as being hypoglycaemic. Values between 2.22 and $2.78 \mathrm{mmol} / \mathrm{l}$ are still regarded as hypoglycaemic if cerebral symptoms of low blood glucose are evident. With many antidiabetic drugs such as sulfonylureas or insulin intensified blood glucose lowering has been associated with an increase in the rate of severe hypoglycemia (Figure 1) [4-6,15]. Severe hypoglycemia has been made responsible for excess deaths in the ACCORD trial [16]. Nineteen of the 41 excess deaths from cardiovascular causes in the study were attributed to "unexpected or presumed cardiovascular disease," which may plausibly be related to or may have been precipitated by hypoglycemia and misclassified as having a cardiovascular cause. Combination therapies, such as a sulfonylurea with insulin, are known to be associated with an increased risk for hypoglycemia and appear to have been used routinely in this study. Hypoglycemia not requiring medical assistance is not trivial however. In these cases a substantial reduction of cognitive and motor function as well as sympathetic counterregulation is observed [17].

\section{Weight gain with antidiabetic drugs}

A positive correlation between weight gain and glycaemic control is well known [18]. Inappropriate weight gain has been demonstrated in landmark diabetes studies with insulin or oral anti-diabetic drugs [19]. Weight gain is associated with accelerated deterioration of beta-cell function in type 2 diabetes, and increases blood pressure and lipid levels in both type 1 and type 2 diabetes. Concerns about increasing weight may be a barrier to initiation or to intensification of insulin therapy. Insulin introduction may be delayed in type 2 diabetes, and patients may under-dose insulin to avoid weightgain [20].

\section{Costs}

There are only three studies on the costs of diabetes in Germany [21-23]: In the CODE-2 Study (Costs of Diabetes in Europe-Type 2) the total expenses for type 2 diabetes were evaluated [22]. The costs per patient compared to the average expenses for health insured patients - increased with complication state from the 1.3-fold (no complications) up to the 4.1-fold (macroand microvascular complications). The second study was the CoDiM (Cost of Diabetes Mellitus) study 


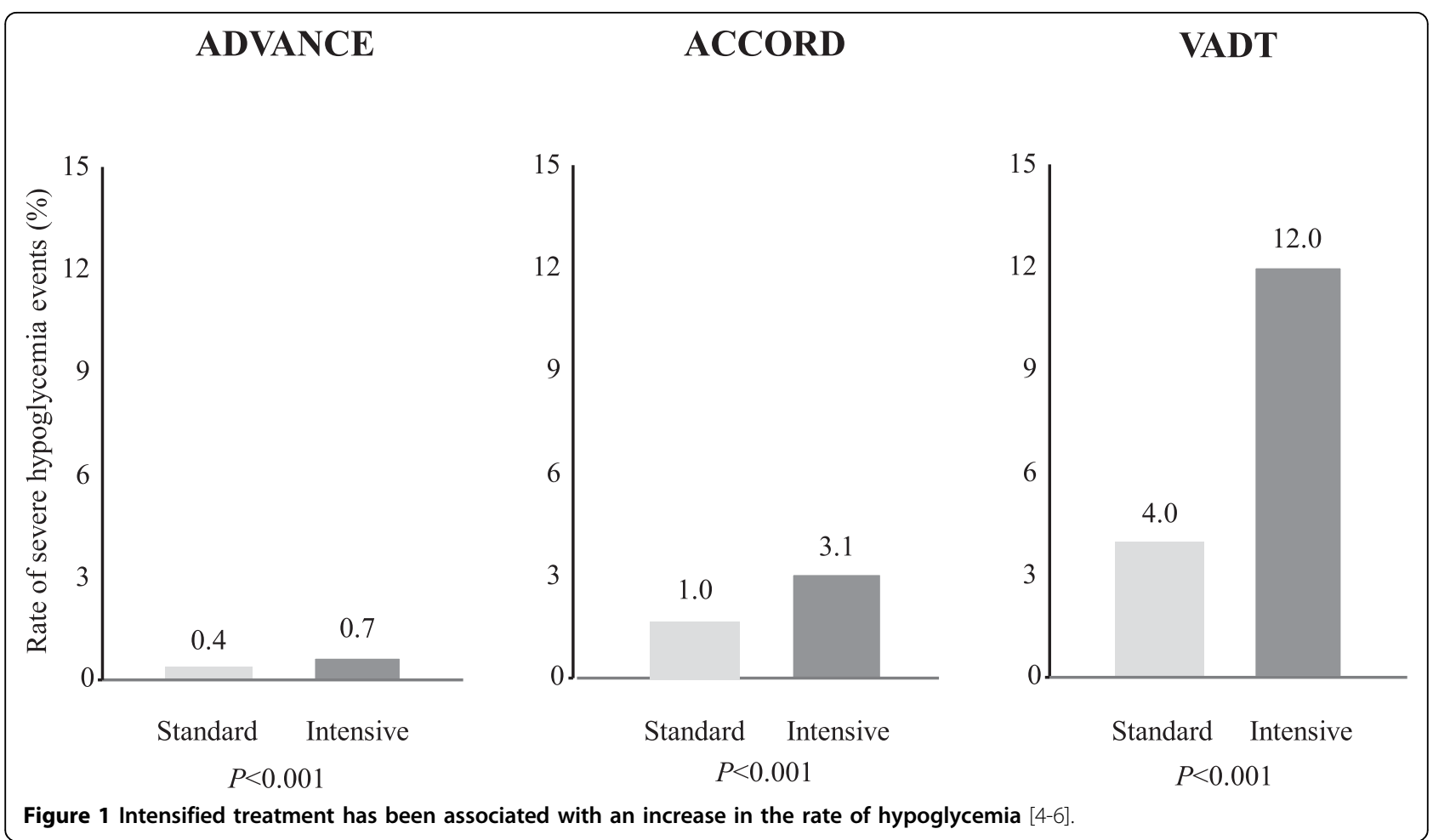

$[23,24]$. Analysis of cost components revealed that the high costs associated with the care of diabetic patients could be largely attributed to inpatient care and overall medication costs. The third study was the German multi-centre, retrospective epidemiological cohort study ROSSO [21]. Total costs of diabetes care was $1,288 €$ for the first treatment year with diagnosed diabetes and rose to $3,845 €$ in year seven. Costs for treating complications dominated already in the first year after diagnosis. The mean direct treatment costs amounted to 3,210 $€$ per patient and year for the first 6.5 years.

\section{Rationale}

Treatment decisions in primary diabetes care are primarily based on evidence from randomized controlled trials. These trials however are confined by strict inand exclusion criteria and patients seen in daily practice differ from the ones documented in clinical trials. In this respect the advantage of registries is to document a variety of patient types and physicians' treatment decisions without influence imposed by the study design. Therefore the external validity of findings in respect to real life conditions is usually high.

With respect to the disease and treatment related complications outlined, we think it is utmost important to gain an understanding of what the patient characteristics are, which disease related laboratory values patients have, what co-morbid diseases are present, what treatment options are used and which complications (e.g. cardiovascular events, hypoglycemia, weight gain) occur during the course of treatment. It is further important to gain an understanding of patient self reported outcomes (PRO) such as treatment satisfaction and health status.

\section{Methods}

Diabetes Treatment Patterns and Goal Achievement in Primary Diabetes Care (DiaRegis) is a prospective, observational, national, multicenter registry with a follow-up of 2 years conducted in Germany. Data were recorded at baseline and will be prospectively documented during follow up visits at $6 \pm 1,12 \pm 2$ and $24 \pm$ 2 months.

This registry is conducted in accordance with the ethical principles that have their origin in the Declaration of Helsinki and adhere to the principles of Good Epidemiology Practice (GEP), and applicable regulatory requirements. The protocol of this registry was approved by the ethics committee of the Landesärztekammer Thüringen in Jena, Germany on March $4^{\text {th }} 2009$. Patients that were enrolled into this registry provided written informed consent. It was further registered with the database of the Verband forschender Arzneimittelhersteller (VFA) [25].

\section{Research Question/Hypothesis}

The aim of the present registry is to evaluate the specific characteristics, treatment patterns, quality of life and diabetes related events of type- 2 diabetic patients who 
failed oral mono- or dual antidiabetic therapy and physicians deemed a change of therapy to be necessary. Because of the increasing risk of hypoglycemia after intensifying antidiabetic treatment when achieving near normal blood glucose values, we chose as a primary objective of DiaRegis to determine the proportion of patients with at least 1 episode of severe hypoglycemia within one year.

Secondary objectives were: 1) To evaluate the number of patients with at least 1 episode of severe, moderate or mild hypoglycemia after 1 and 2 years respectively; 2) To evaluate the number of hypoglycaemic events per patient after 1 and 2 years, respectively; 3) To evaluate the glycaemic profile; 4) To evaluate a change in measured body weight over the course of the study; 5) To evaluate fasting blood glucose and postprandial glucose of patients; 6) To evaluate the health status (EQ-5D) and treatment satisfaction (DTSQ); 7) To evaluate co-morbid disease conditions; 8) To determine costs associated with hypoglycemia; 9) To determine costs associated with therapy/treatment and disease related complications.

\section{Definitions}

Hypoglycemia was classified as follows. In case of severe hypoglycemia the patient seeks medical attention or is admitted to hospital because of hypoglycemia. In case of moderate hypoglycemia patients experience symptoms of hypoglycemia and require assistance from a second person (a relative or friend, etc.), but no medical attention is necessary. Mild hypoglycemia is determined from blood glucose measurements $(<2.22 \mathrm{mmol} / \mathrm{l} ; 40 \mathrm{mg} / \mathrm{dl}$ in any case; $2.22-2.78$ or $50 \mathrm{mg} / \mathrm{dl}$ in case of symptoms) and is manageable without foreign help.

\section{Physician selection}

Physicians have been selected based on a conditioned random sampling method. For this purpose a physician database with about 9.350 office based physicians (general practitioners, internists, practitioners and diabetologists) who treat patients with type 2 diabetes were asked in writing, to evaluate the possibility of participation. For this purpose physicians were requested to complete a questionnaire to check on whether they fulfil criteria for participation. Only physicians with at least 150 patients with type 2 diabetes under regular medical care were eligible to ensure, that a broad treatment spectrum will be covered and to secure that physicians were able to recruit patients fast and efficient and to receive a random distribution across all German regions. The sampling strategy should thus provide a representative dataset for the description of oral antidiabetic treatment patterns in Germany.

Physicians were contacted once and informed about the background and aims of the study. They were asked to complete a fax questionnaire indicating their eligibility and consent to participate in the study (or to give a reason for non-participation). The response further included site information about personal data as well as equipment of the site, especially with respect to the registry requirements. Non-participants will be assessed for comparability with participating physicians regarding physician and office characteristics.

1-2 weeks prior to the study, participating physicians received detailed information material, physician and patient questionnaires and access to a secure website for the entry of patient documentation. A telephone hotline was provided by the $\mathrm{CRO}$ and by the Institut für Herzinfarktforschung.

\section{Patient selection}

Inclusion Criteria were as follows: 1) Patients with type2 diabetes; 2) Age $\geq 40$ years; 3) The treating physician indicated that blood glucose lowering therapy needed to be stepped up or changed, e.g. because glycaemic targets were not met or medication not safe and/or not tolerated; 4) Oral mono- or dual combination therapy (no insulin/no GLP-1 analogue); 5) The physician actually added another drug/switches therapy; 6) Provision of patient informed consent.

The following exclusion criteria applied: 1) Patients not under regular supervision of the treating physician for the duration of the study; 2) Patients with type 1 diabetes; 3) Pregnancy (gestational diabetes); 4) Diabetes secondary to malnutrition, infection or surgery; 5) Maturity onset diabetes of the young; 6) Known cancer or limited life expectancy; 7) Further reasons for exclusion were conditions that made it impossible or highly problematic for the patient to participate and to come to the follow-up visits (such as poor German language skills, serious disabilities or diseases, hospitalization) and acute emergencies; 8) Participation in a clinical trial.

The following subgroups are pre-defined and will be further explored: 1) patients that are prescribed insulin (with or without OAD) as the next step; 2) patients that are prescribed any combination with a DPP-4 inhibitor; 3) patients that are prescribed a combination of metformin and sulfonylureas; 4 ) patients that are prescribed a combination of metformin and a thiazolidinedione; 5) patients that are prescribed a combination of sulfonyureas and a thiazolidinedione; 6) patients that are prescribed any other combination including those receiving a GLP-1 analogue/mimetic.

\section{Documented variables}

Table 1 gives an overview of variables obtained during regular visits at baseline and during follow-up including those from the physicians and patient questionnaires. Figure 2 illustrates the study design. Further to these 
Table 1 Study flow chart

\begin{tabular}{|c|c|c|c|c|}
\hline \multirow{2}{*}{$\begin{array}{l}\text { Evaluation } \\
\text { Month }\end{array}$} & \multicolumn{4}{|c|}{ Observational Phase } \\
\hline & Mo & M6 ( $\pm 1 \mathrm{M})$ & M12 ( $\pm 2 \mathrm{M})$ & $M 24( \pm 2 M)$ \\
\hline \multicolumn{5}{|l|}{ Demographics \& Co-morbidity } \\
\hline Inclusion/Exclusion Criteria & $x$ & & & \\
\hline Patient Identification & $x$ & $x$ & $x$ & $x$ \\
\hline Date of visit & $x$ & $x$ & $x$ & $x$ \\
\hline Date of consent & $x$ & & & \\
\hline Demographics & $x$ & & & \\
\hline Physical examination & $x$ & $x$ & $x$ & $x$ \\
\hline Diabetes history & $x$ & & & \\
\hline Diabetic complications and co-morbidity & $x$ & $x$ & $x$ & $x$ \\
\hline Pharmacotherapy & $x$ & $x$ & $x$ & $x$ \\
\hline \multicolumn{5}{|l|}{ Laboratory values: } \\
\hline $\mathrm{TC}, \mathrm{TG}, \mathrm{HDL}-\mathrm{C}, \mathrm{LDL}-\mathrm{C}$ & $x$ & $x$ & $x$ & $x$ \\
\hline Serum-Creatinine, Micro-, Macroalbuminuria & $x$ & $x$ & $x$ & $x$ \\
\hline CRP & $x$ & $x$ & $x$ & $x$ \\
\hline$H b_{A 1 c}, F P G, P P G$ & $x$ & $x$ & $x$ & $x$ \\
\hline Non-drug intervention & $x$ & $x$ & $x$ & $x$ \\
\hline Hypoglycaemic events & $x$ & $x$ & $x$ & $x$ \\
\hline \multicolumn{5}{|l|}{ Body Weight } \\
\hline Body weight and height & $x$ & $x$ & $x$ & $x$ \\
\hline Hip and waist circumference & $x$ & $x$ & $x$ & $x$ \\
\hline EQ-5D, DTSQ & $x$ & & $x$ & $x$ \\
\hline Hypoglycemia Awareness Questionnaire & $x$ & $x$ & $x$ & $x$ \\
\hline WHO-5 & $x$ & & $x$ & $x$ \\
\hline
\end{tabular}

TC, total cholesterol; TG, triglycerides; $\mathrm{HDL}$, high density lipoprotein; LDL, low density lipoprotein; $\mathrm{Hb}_{\mathrm{A1}}$, glycosylated haemoglobin $\mathrm{A1C}$; CRP, $\mathrm{C}$-reactive protein; FPG, fasting plasma glucose; PPG, post-prandial glucose; EQ-5D, EuroQol-5D; DTSQ, Diabetes Treatment Satisfaction Questionnaire; WHO, World Health Organization

variables patients received a patient diary for the documentation of hypoglycaemic events (date, measured blood glucose, severity of hypoglycemia, glucagon use) during the 2 year follow-up.

\section{Monitoring}

To reduce the logistics of coordinating such a nationwide study, participating physicians received no other instructions than the information material sent to them by mail prior to the survey. Further they were contacted within a few days prior to commencement of the study to ensure compliance with the registry protocol. To control for a proper procedure and to ensure the robustness of the data obtained, a specifically adapted monitoring system was designed to meet the logistic needs. This monitoring concept included telephone and fax monitoring and random on-site visits. The monitors were specifically trained prior to start of the study, especially in terms of survey procedures and criteria for follow-up appointments.

On-site visits were performed within the month following the recruitment into the registry, with a focus on quality of data and measurements. Monitoring visits are conducted in at least $10 \%$ of the participating sites randomly selected. Monitoring is split into 4 parts suggesting to monitor $3 \%$ of the sites $(n=13)$ after enrolment of patients, $3 \%$ after 6 months $(n=13), 2 \%$ after 12 months $(n=9)$ and $2 \%$ after 24 months $(n=9)$. The observed quality problems and errors at the monitored sites allow an estimation of the overall error rate of the study. For every site monitored selected patient data were to be checked for integrity and compared with the source data. The physician or physician assistants were requested to rectify observed errors.

\section{Database Methodology}

Data entry was performed by the physician or study nurse via a secure website directly into an electronic database. This approach allowed online checks for plausibility and integrity.

Data from the patient questionnaire (paper version) which was asked to be completed by the patient during the visit were transferred to the CRO appointed. The questionnaires were scanned and transferred to the Institut für Herzinfarktforschung for evaluation.

All data sets were checked for incorrect data and corrected if applicable; all corrections are documented. All data sets are submitted for biostatistic analysis. 


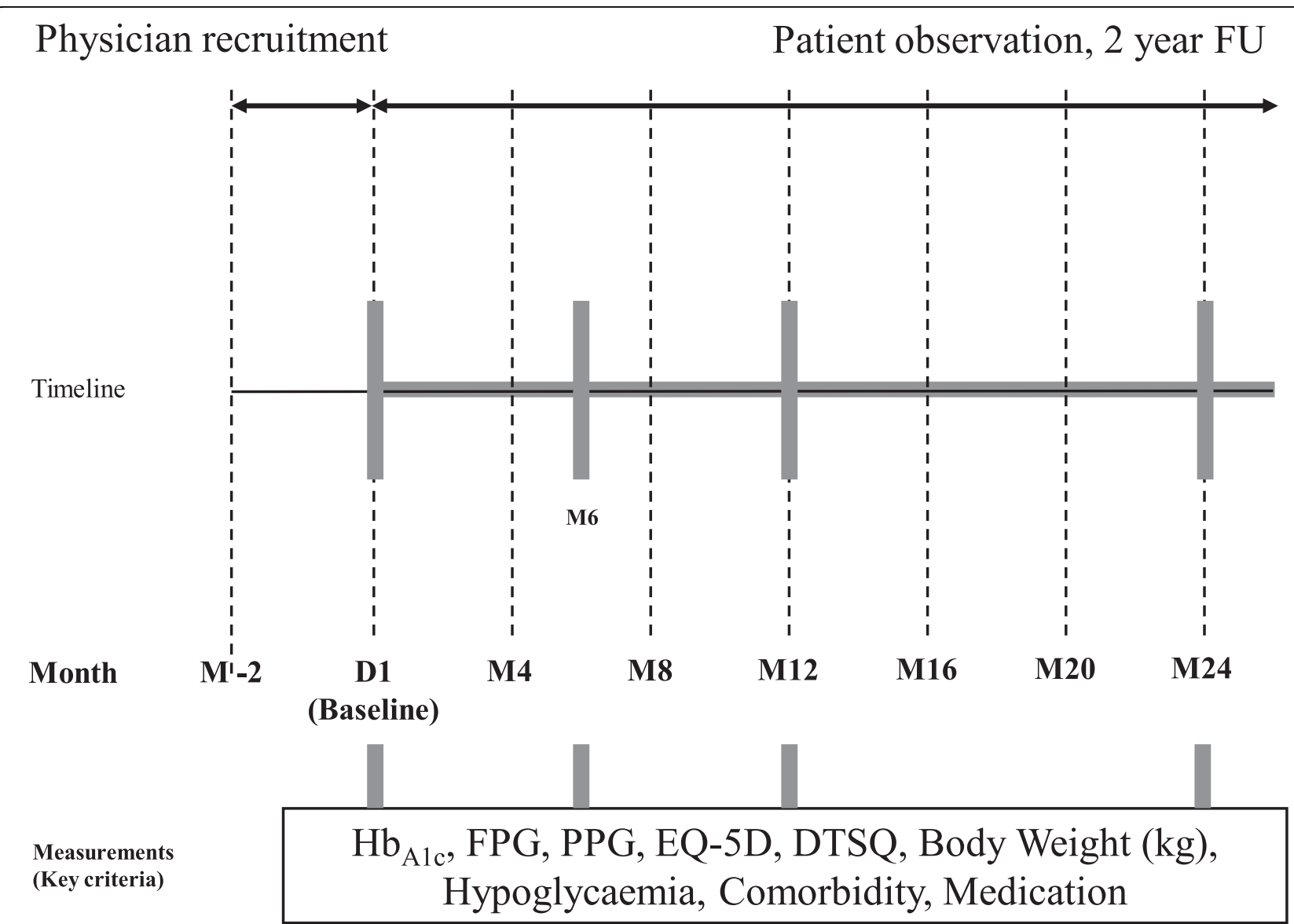

Figure 2 Graphical study design. M, month(s); FU, follow-up; D, Day; FPG, fasting plasma glucose; PPG, post-prandial glucose; EQ-5D, EuroQol5D; DTSQ, Diabetes Treatment Satisfaction Questionnaire

\section{Statistical Methods}

Descriptive statistics (mean, standard deviation, range, percentiles, proportions etc.) are calculated for all patients and the pre-specified subgroups. Chi square tests or Wilcoxon rank sum tests are used where appropriate to investigate differences in distributions of variables by subgroups. Multivariable analyses are conducted as necessary to adjust for other covariates. All statistical analyses are conducted using the statistical software package SAS 9.1 (SAS Institute, Cary, NC, USA).

The analysis is planned to: 1) Describe the baseline patient characteristics, including risk factors, co-morbidity, pharmacotherapy received, switching between therapeutic options and a number of PRO measures; 2) Estimate the incidence and frequency of hypoglycaemic events after 1 and after 2 years, as well as changes in PRO measures at each visit; 3) Analyse any associations between the choice of pharmacotherapy and outcomes after 1 and after 2 years; 4) Identify independent determinants of hypoglycaemic events using multivariable statistics.
A specific objective of DiaRegis is to estimate the cost of hypoglycemia. Therefore it will consider the number of patients with events and the number of events per patient.

\section{Sample Size}

The primary objective for sample size consideration is to estimate the proportion of patients with at least 1 episode of severe hypoglycemia within one year. Based on recently reported rates of severe hypoglycaemic events between $0.4 \%$ and $3.1 \%$ per year, a conservative estimation of the overall rate of severe hypoglycaemic events of $1.5 \%$ over 1 year and a desirable precision of the estimate of $\pm 0.337 \%$ the sample size had to be 5000 patients. In case of a reduced recruitment of 3,900 patients or 3,600 patients an estimate precision of $\pm 0.382 \%$ and $\pm 0.397 \%$ was expected.

\section{Results}

313 primary care offices included patients into DiaRegis. 109 were general practitioners, 116 diabetologists, 84 internists and 4 others (Figure 3). Between June 2009 


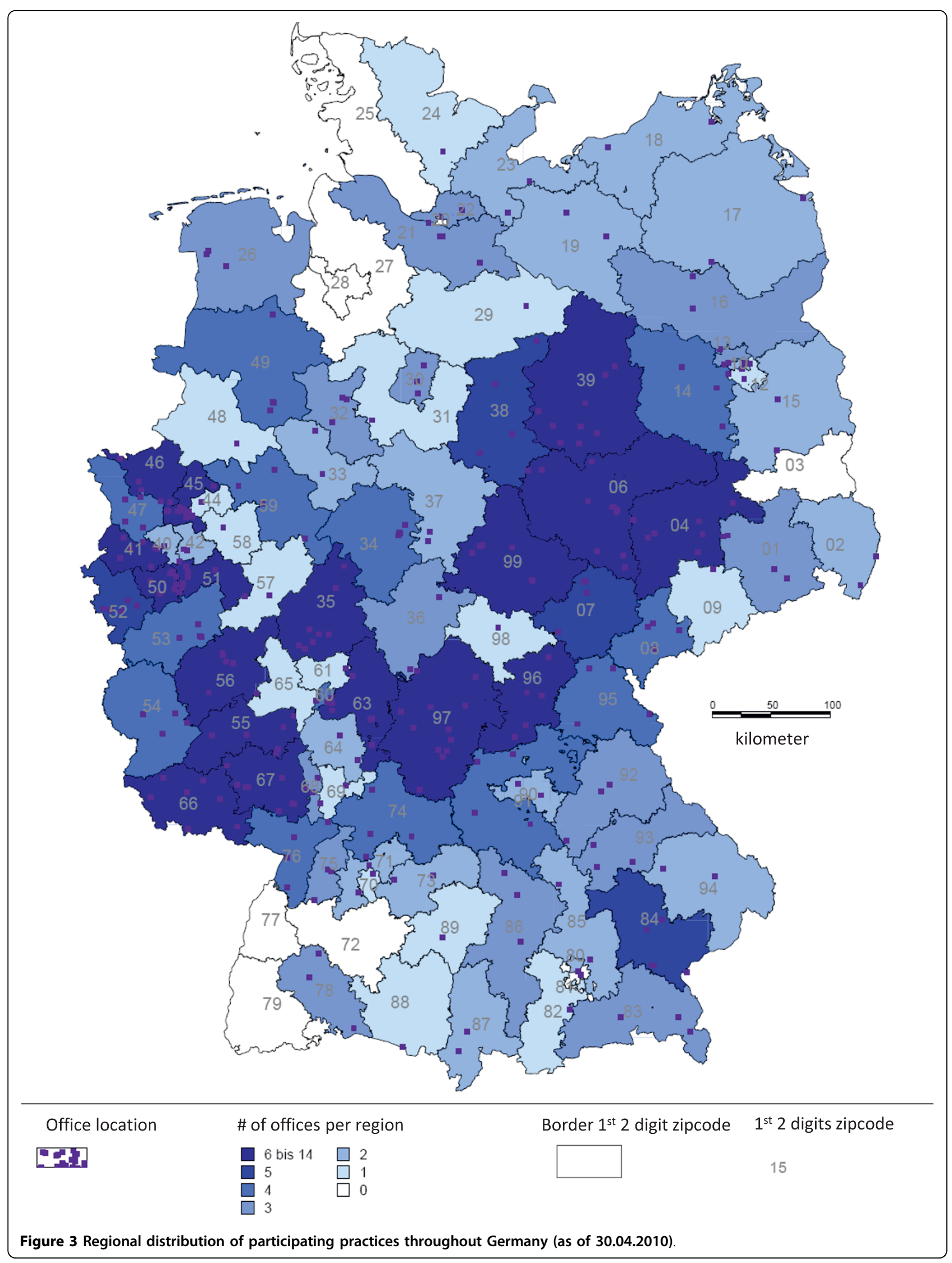


and March 2010 these physicians included a total of 4,048 patients. Of these 238 patients were excluded because in- and exclusion criteria were not met, including 7 patients who withdrew informed consent. Therefore 3810 patients out of 313 practices were available for the description of baseline patient characteristics (Figure 4).

\section{Patient characteristics and laboratory values at baseline}

Of the 3810 patients available for the baseline analysis $46.7 \%$ were female; patients had median diabetes duration of 5.5 years and most were obese with respect to $\mathrm{BMI}$ or waist circumference. $\mathrm{Hb}_{\mathrm{A} 1 \mathrm{c}}$ at baseline was $7.4 \%$, fasting plasma glucose $142 \mathrm{mg} / \mathrm{dl}$ and postprandial glucose $185 \mathrm{mg} / \mathrm{dl}$ (for further baseline characteristics see Table 2). In comparison men were slightly younger, and had higher blood glucose values $\left(\mathrm{Hb}_{\mathrm{A} 1 \mathrm{c}}\right.$, fasting and postprandial glucose) along with significant differences in lipid values $(\mathrm{p}<0.0001)$.

\section{Risk factors and co-morbid conditions at baseline}

$11.9 \%$ of patients were smoking and $62.9 \%$ were drinking any alcohol (men $>$ women; $\mathrm{p}<0.0001$; Table 3 ). On the other hand more men were doing any sports even if seldom ( 45.0 vs. $34.6 \%$; OR 1.55 ; $95 \%$ CI 1.35 1.78). While the prevalence of coronary artery disease (23.4 vs. $11.7 \%$; OR 2.31 ; $95 \% \mathrm{CI} 1.93-2.76$ ) and myocardial infarction (38.9 vs. $24.1 \%$ of those with CAD; OR 2.00; $95 \%$ CI $1.38-2.92$ ) was higher in men than in women, clinical evidence of relevant depression (indicated by the treating physician) was less frequent in men (3.6 vs. 7.4\%; OR 0.47 ; $95 \%$ CI $0.35-0.63$; $\mathrm{p}<0.0001)$.

\section{Drug utilization}

$68.6 \%$ of patients received oral monotherapy, $31.4 \%$ dual oral combination therapy. The most frequent antidiabetic agent used in monotherapy was metformin (79.0\%) followed by sulfonylureas (14.8\%) (Figure 5, panel A).

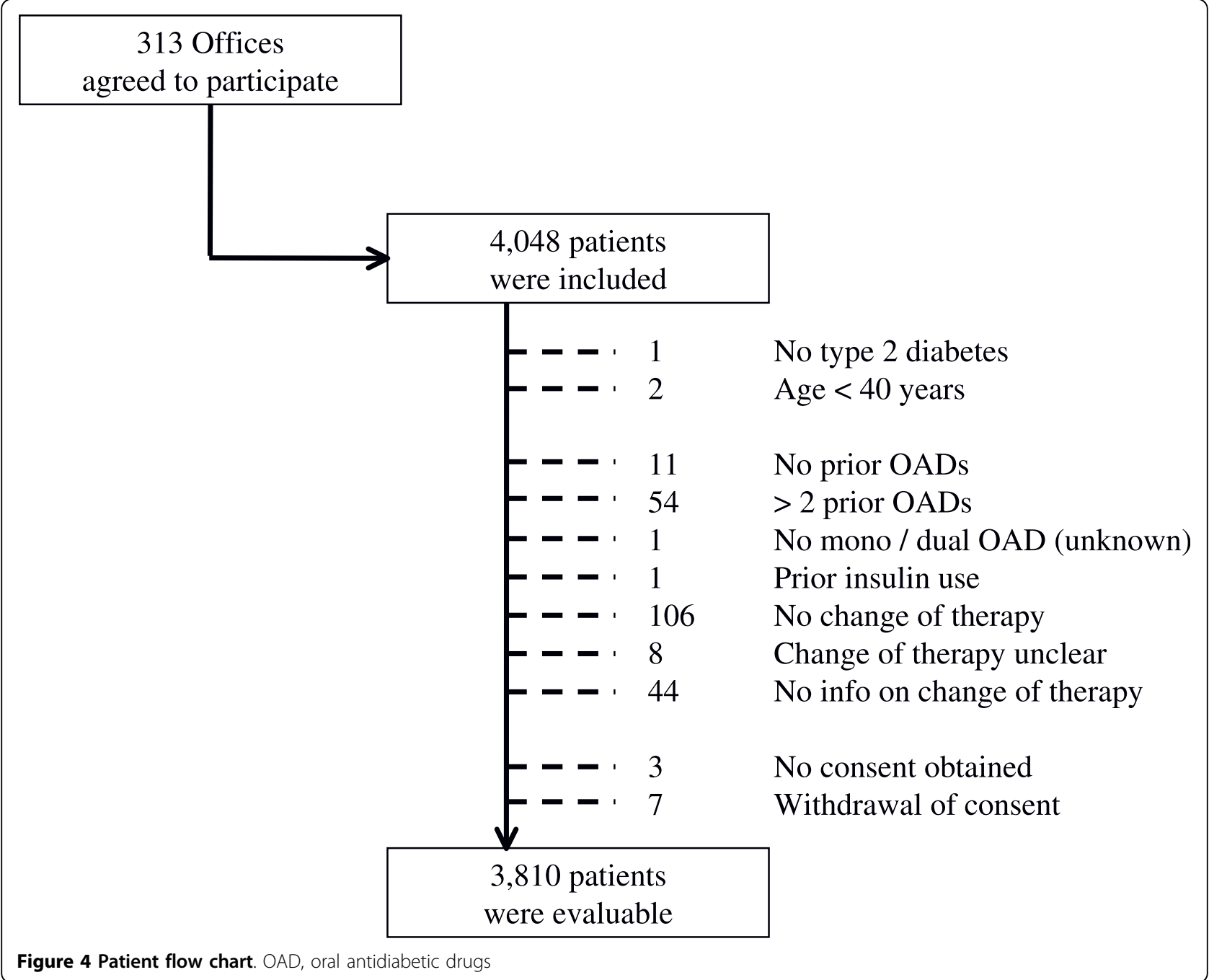


Table 2 Patient characteristics and laboratory values at baseline

\begin{tabular}{|c|c|c|c|c|}
\hline & Total $(n=3,810)$ & Men $(n=2,033)$ & Women $(n=1,777)$ & p-value (m vs. f) \\
\hline Age (years) & $65.9(57.6-72.9)$ & $64.7(56.8-72.0)$ & $67.2(58.6-74.1)$ & $<0.0001$ \\
\hline Diabetes duration (years) & $5.5(2.9-9.4)$ & $5.5(2.8-9.3)$ & $5.6(3.0-9.4)$ & n.s. \\
\hline BMI $\left(\mathrm{kg} / \mathrm{m}^{2}\right)$ & $30.0(27.0-35.0)$ & $30.0(27.0-34.0)$ & $31.0(28.0-36.0)$ & $<0.0001$ \\
\hline Waist circumference $(\mathrm{cm})$ & $106(98-116)$ & $108(100-118)$ & $104(95-114)$ & $<0.0001$ \\
\hline Total cholesterol (mg/dl) & $205(177-232)$ & 199 (172-228) & $211(185-236)$ & $<0.0001$ \\
\hline HDL-Cholesterol (mg/dl) & $47(40-57)$ & $44(38-52)$ & $52(44-61)$ & $<0.0001$ \\
\hline LDL-Cholesterol (mg/dl) & $120(98-145)$ & $116(93-142)$ & $123(103-147)$ & $<0.0001$ \\
\hline Triglycerides (mg/dl) & $176(127-243)$ & $184(129-266)$ & $169(125-228)$ & $<0.0001$ \\
\hline $\mathrm{Hb}_{\mathrm{A} 1 \mathrm{c}}(\mathrm{mg} / \mathrm{dl})$ & $7.4(6.8-8.3)$ & $7.5(6.9-8.4)$ & $7.3(6.8-8.1)$ & $<0.0001$ \\
\hline Fasting plasma glucose (mg/dl) & $142(119-171)$ & $144(121-175)$ & $140(118-168)$ & $<0.01$ \\
\hline Postprandial glucose (mg/dl) & $185(155-221)$ & $189(159-225)$ & $179(151-216)$ & $<0.0001$ \\
\hline
\end{tabular}

BMI, body mass index; $\mathrm{HDL}$, high density lipoprotein; LDL, low density lipoprotein; $\mathrm{Hb}_{\mathrm{A} 1 \mathrm{c}}$ glycosylated haemoglobin A1c

In patients with dual oral combination therapy the most frequent combinations were metformin with sulfonylureas $(55.8 \%)$, glitazones (15.5\%), DPP-4 inhibitors (12.6\%) and glinides (8.6\%), respectively (Figure 5 , panel B). Differences between male and female patients were negligible and not significant except for a slightly more frequent use of glinides in men (10.1 vs. $6.8 \%$; $\mathrm{p}<0.05)$.

At the inclusion visit patients' oral antidiabetic agents were either adjusted, added, substituted for another oral antidiabetic agent or insulin or a GLP-1 analogue was added. Being asked which reason led to this decision the physicians indicated that not meeting blood glucose targets was the most frequent reason (86.9\%). Hypoglycemia, weight gain, adverse events and unclassified reasons were much less important (Figure 6, panel A).
After therapy change the use of sulfonylureas was slightly reduced (26.3 vs. $28.9 \%$ ), while the use of DPP-4 inhibitors increased significantly (38.8 vs. $4.9 \%)$. Newly introduced were GLP-1 analogous (9.2\%) and insulin (17.3\%) (Figure 6, panel B). Antidiabetic drug therapy was not statistically different between men and women at baseline. After therapy change only the use of metformin (85.6 vs. $83.3 \%$; OR 1.19 ; $95 \%$ CI $1.00-1.42)$ and glitazones (11.6 vs. $8.8 \%$; OR 1.35 ; 95\%CI $1.09-1.67)$ was higher in men.

\section{Discussion}

DiaRegis is a large prospective registry evaluating disease and treatment related complications in patients with type-2 diabetes in Germany. These data

Table 3 Risk factors and co-morbid conditions at baseline

\begin{tabular}{|c|c|c|c|c|c|}
\hline & Total $(n=3,810)$ & Men $(n=2,033)$ & Women $(n=1,777)$ & OR $(95 \% \mathrm{Cl})$ & $\mathrm{p}$-value \\
\hline Smoker & 11.9 & 14.4 & 9.1 & $1.69(1.37-2.08)$ & $<0.0001$ \\
\hline Any alcohol, even rare & 62.9 & 79.9 & 43.6 & $5.15(4.38-6.06)$ & $<0.0001$ \\
\hline Any Sports, even rare & 40.1 & 45.0 & 34.6 & $1.55(1.35-1.78)$ & $<0.0001$ \\
\hline Dyslipidemia & 63.3 & 64.7 & 61.6 & $1.14(1.00-1.31)$ & $<0.05$ \\
\hline Hypertension & 84.4 & 83.6 & 85.3 & $0.88(0.74-1.05)$ & n.s. \\
\hline Malignancy & 2.0 & 1.8 & 2.2 & $0.83(0.52-1.30)$ & n.s. \\
\hline Coronary artery disease & 17.9 & 23.4 & 11.7 & $2.31(1.93-2.76)$ & $<0.0001$ \\
\hline Prior Ml & 34.4 & 38.9 & 24.1 & $2.00(1.38-2.92)$ & $<0.001$ \\
\hline Prior stroke/TIA & 4.6 & 5.0 & 4.2 & $1.18(0.87-1.60)$ & n.s. \\
\hline PAD & 6.0 & 7.7 & 4.1 & $1.95(1.46-2.60)$ & $<0.0001$ \\
\hline Amputation* & 0.9 & 1.2 & 0.6 & $2.20(1.05-4.60)$ & $<0.05$ \\
\hline Heart failure & 9.9 & 10.4 & 9.3 & $1.13(0.91-1.40)$ & n.s. \\
\hline Autonomous neuropathy & 3.4 & 3.7 & 2.9 & $1.28(0.89-1.84)$ & n.s. \\
\hline Symptoms of peripheral neuropathy & 14.4 & 15.7 & 12.8 & $1.27(1.06-1.53)$ & $<0.05$ \\
\hline NPDR & 3.8 & 3.6 & 3.9 & $0.91(0.65-1.28)$ & n.s. \\
\hline PDR & 0.5 & 0.5 & 0.5 & $0.97(0.39-2.40)$ & n.s. \\
\hline Blindness & 0.2 & 0.2 & 0.2 & $1.17(0.26-5.22)$ & n.s. \\
\hline Clinically relevant depression & 5.4 & 3.6 & 7.4 & $0.47(0.35-0.63)$ & $<0.0001$ \\
\hline
\end{tabular}

PDR, proliferative diabetic retinopathy; MI, Myocardial Infarction; NPDR, non-proliferative diabetic retinopathy; PAD, peripheral arterial disease; TIA, transitory ischemic attack; OR, odds ratio; $\mathrm{Cl}$, confidence interval; * toe, foot or lower extremity 
Percent of all patients on oral monotherapy $(68.6 \%)$

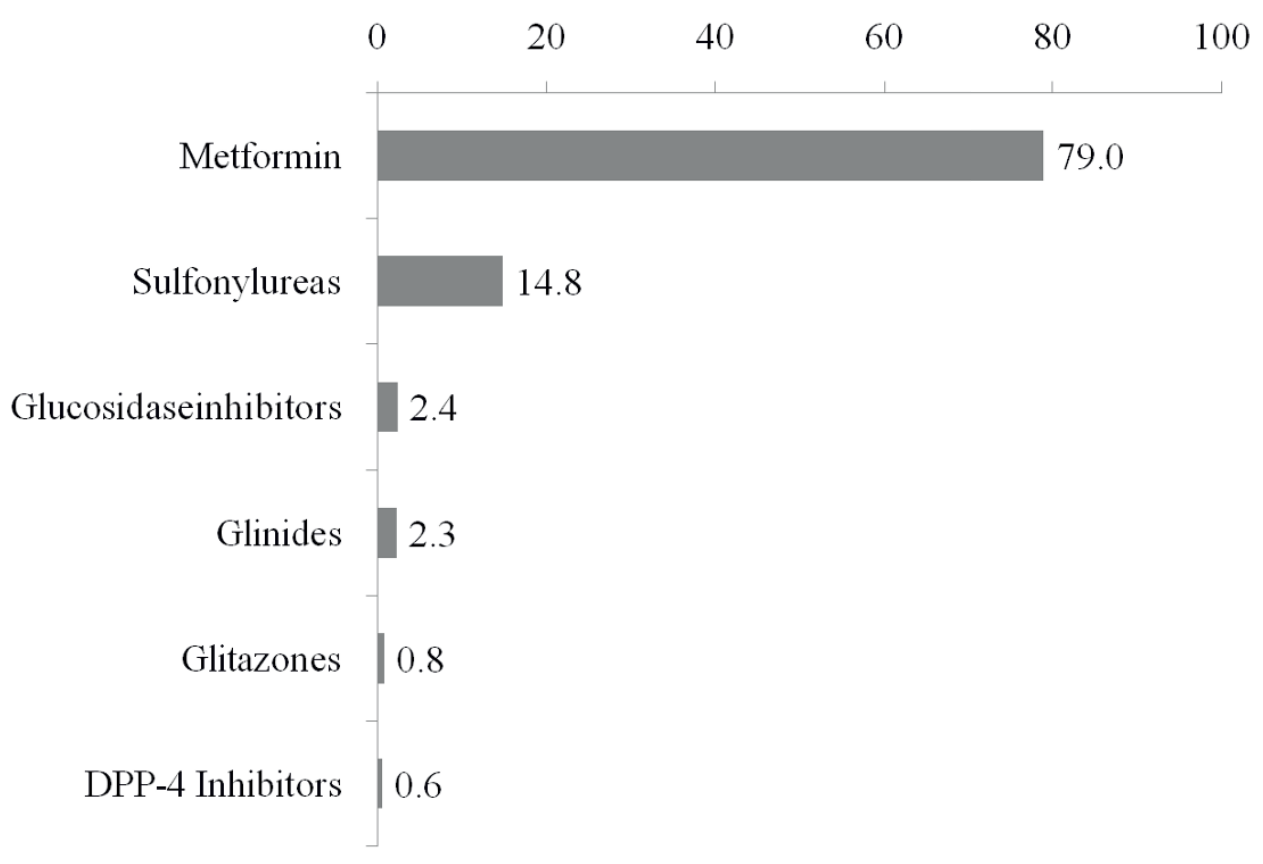

Percent of all patients on dual oral combination therapy (31.4\%)

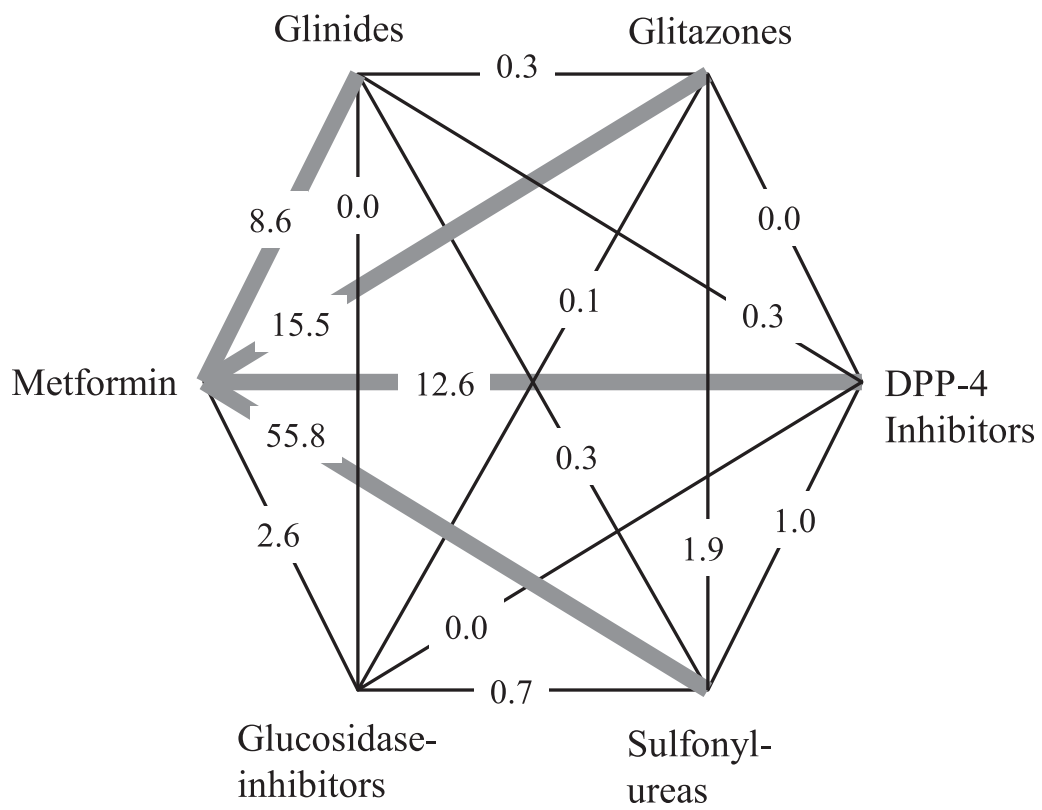

Figure 5 Drug utilization in DiaRegis of patients on oral monotherapy (68.6\% of all patients) (panel A) and on dual oral combination therapy (31.4\%of all patients) (panel B). 


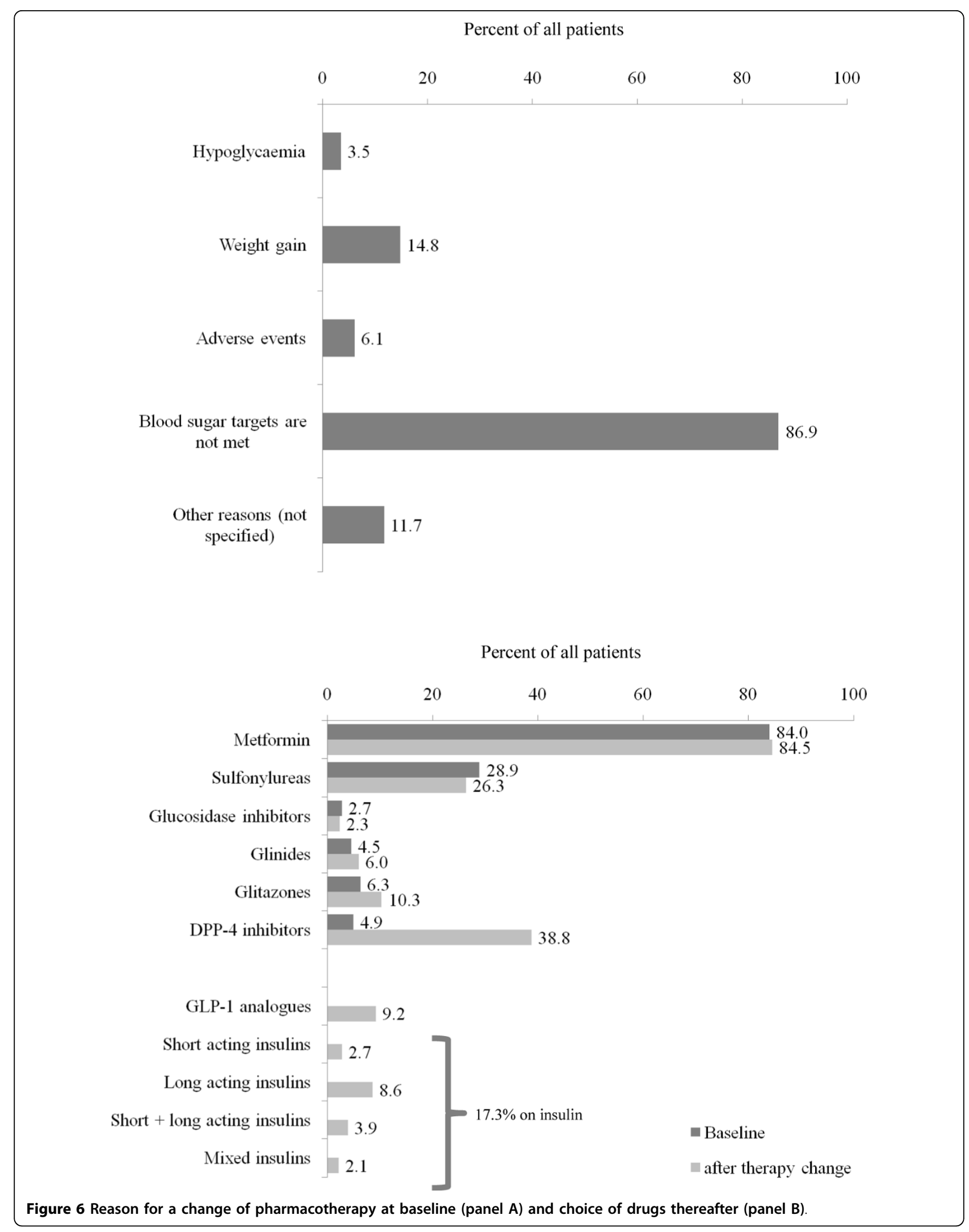


supplement evidence obtained from randomized controlled trials by documenting drug use in specific patient populations, concomitant diseases, concurrent pharmacotherapies and are thus highly relevant for daily practice.

\section{Need for a prospective observational registry}

There are a number of epidemiological studies which documented (among other aspects) the treatment of type- 2 diabetes. Table 4 gives an overview about studies closely related to the research question of DiaRegis. These included the 2001 HYDRA study [26], the 2003 DETECT study [27] and the studies CODE-2 $[22,28,29]$, ROSSO [21,30], DUTY [31], CoDiM [23] and DIG [32,33]. These have aimed at describing the situation of diabetic patients in primary care in Germany. Finally SWEETHEART is a prospective registry in patients with type- 2 diabetes and acute myocardial infarction with or without ST elevation within the previous 24 h. It started in October 2006 and included 2,772 patients in 31 hospitals in Germany but results have been presented [34] but not published yet.

Most of these studies however either had a detailed look on the prevalence of type-2 diabetes in primary care practice (HYDRA and DETECT), the co-morbidity burden (DETECT), the costs (CODE-2, CoDiM and ROSSO), on self-monitoring of blood glucose (ROSSO) or on the effect of tailored intervention on target achievement (DUTY, DIG). Most of these did not consider nutritional/dietary aspects, as well as a more customized approach to the recruited patients' lifestyle and physical activity $[35,36]$. Some were also retrospective in design (CODE-2, CoDiM and ROSSO). Moreover most epidemiological studies are rather old, and contemporary data are scarce [32,33].

The particular value of DiaRegis relates to the prospective evaluation of antidiabetic therapy in patients being prone to disease and treatment related complications such as hypoglycaemia. The prospective design will improve data quality in comparison to other registries because a structured assessment and documentation is usually more complete and consistent than retrospective analyses of existing data which have been obtained for other purposes. With this respect the monitoring concept in this registry is important (tables 4 and 5), in that the validation of data with the respective source data will further improve data quality. This has previously been shown to be effective in other registries $[37,38]$.

\section{Conclusions}

DiaRegis is a large, prospective registry in primary diabetes care to document the course and outcomes of patients with type-2 diabetes who failed the initial approach of oral mono/dual antidiabetic therapy. The two year follow-up will allow for a prospective evaluation of these patients during multiple adjustments of therapy. The results of this registry will help to understand how the degree of diabetes control and treatment-related events such as hypoglycemia or diabetesrelated complications impact patient reported outcomes. It further might give insight in how to improve patient care in type 2 diabetes with the ultimate goal to improve outcomes and possibly prolong life.

Table 4 Comparison of DiaRegis with other existing registries (part I)

\begin{tabular}{|c|c|c|c|c|}
\hline & DiaRegis & CODE-2 & CoDiM & ROSSO \\
\hline Reference & & {$[22]$} & {$[23,24]$} & {$[21]$} \\
\hline No. of physicians & 313 & 135 & n.a. & 192 \\
\hline No. of patients & 3,810 & 809 & 26,971 & 3,286 \\
\hline Recruitment & 06/2009-03/2010 & 1 year (1998) & 2001 & 1995-2003 \\
\hline Follow-up & 2 years & none & none & Min. 4 years \\
\hline Design & Prospective cohort & $\begin{array}{l}\text { Retrospective, cross- } \\
\text { sectional }\end{array}$ & Database analysis & Retrospective cohort \\
\hline $\begin{array}{l}\text { Monitoring for } \\
\text { data verification }\end{array}$ & Yes (10\%) & None & None & None \\
\hline Proportion T2D & $100 \%$ & $100 \%$ & $100 \%$ & $100 \%$ \\
\hline Patients & $\begin{array}{l}\text { Patients on oral mono- or dual } \\
\text { antidiabetic combination therapy }\end{array}$ & $\begin{array}{l}\text { Patients with type-2 } \\
\text { diabetes mellitus }\end{array}$ & $\begin{array}{l}\text { Patients with type-2 } \\
\text { diabetes mellitus }\end{array}$ & $\begin{array}{l}\text { Patients with newly diagnosed } \\
\text { type-2 diabetes mellitus }\end{array}$ \\
\hline Median age (years) & 65.9 & 66 & n.a. & Mean $62.5 \pm 9.6$ \\
\hline Female (\%) & 46.7 & 52 & n.a. & 51.4 \\
\hline BMI (median) & 30.0 & 28 & n.a. & Mean $29.8 \pm 5.1$ \\
\hline Focus & $\begin{array}{l}\text { Hypoglycemia incidence with } \\
\text { antidiabetic drug use }\end{array}$ & $\begin{array}{l}\text { Costs of type-2 } \\
\text { diabetes }\end{array}$ & Costs of diabetes & Costs of diabetes \\
\hline
\end{tabular}

n.a., not available 
Table 5 Comparison of DiaRegis with other existing registries (part II)

\begin{tabular}{|c|c|c|c|c|}
\hline & HYDRA & DETECT & DUTY & DIG \\
\hline Reference & {$[26,39]$} & {$[27]$} & {$[31]$} & {$[32,33]$} \\
\hline No. of physicians & 1,912 & 3,188 & n.a. & 238 \\
\hline No. of patients & 45,125 & 55,518 & 59,035 & 4,020 \\
\hline Recruitment & 09/2001 & 09/2003 & $2001-2003$ & $2002-2004$ \\
\hline Follow-up & none & 1 and 4 years & 9 months & 4 years \\
\hline Design & Cross-sectional, no follow-up & $\begin{array}{l}\text { Cross-sectional with a prospective } \\
\text { follow-up of a subgroup }\end{array}$ & Prospective cohort study & Prospective cohort study \\
\hline $\begin{array}{l}\text { Monitoring for } \\
\text { data verification }\end{array}$ & None & None & None & None \\
\hline Proportion T2D & $16.1 \%$ & $14.1 \%$ & $100 \%$ & $100 \%$ \\
\hline Patients & Any patient in primary care & Any patient in primary care & $\begin{array}{c}\text { Type-1 or type-2 diabetes } \\
\text { mellitus }\end{array}$ & Type-2 Diabetes mellitus \\
\hline $\begin{array}{l}\text { Median age } \\
\text { (years) }\end{array}$ & 52.4 & Mean $53.9 \pm 17.3$ & $64.4 \pm 11.7$ & Mean $61.8 \pm 8.1$ \\
\hline Female (\%) & 60.0 & 59.2 & 50.9 & 46.8 \\
\hline BMI (median) & n.a. & Mean $26.8 \pm 5.3$ & Mean $28.7 \pm 4.8$ & Mean $30.7 \pm 5.2$ \\
\hline Focus & $\begin{array}{l}\text { Prevalence of hypertension, } \\
\text { diabetes and microalbuminuria }\end{array}$ & $\begin{array}{l}\text { Co-morbidity burden of patients } \\
\text { with diabetes }\end{array}$ & $\begin{array}{l}\text { Effect of tailored intervention } \\
\text { on target achievement }\end{array}$ & $\begin{array}{l}\text { Application of guidelines } \\
\text { in clinical practice }\end{array}$ \\
\hline
\end{tabular}

n.a., not available

\section{Acknowledgements}

Winicker Norimed GmbH, Nürnberg is the responsible Clinical Research Organization. The Institut für Herzinfarktforschung, Ludwigshafen, Germany is responsible for data collection and statistical evaluation. We wish to acknowledge the excellent support of Mirjam Strasser (representative of the Winicker Norimed $\mathrm{GmbH}$ ) and Sonja Frey, Benjamin Weidig (representative of the Institut für Herzinfarktforschung) during the preparation and the conduct of the registry. In addition, we wish to acknowledge the support of all participating physicians and patients without whom the present registry would have not been possible.

\section{Author details}

${ }^{1}$ Institute for Cardiovascular Pharmacology and Epidemiology, Mahlow, Germany. ${ }^{2}$ Bristol Myers Squibb, Medical Department, Munich, Germany. ${ }^{3}$ Institut für Herzinfarktforschung Ludwigshafen an der Universität Heidelberg, Ludwigshafen, Germany. ${ }^{4}$ AstraZeneca, Medical Department, Wedel, Germany. ${ }^{5}$ Herz- und Diabeteszentrum Nordrhein-Westfalen in Bad Oeynhausen, Universitätsklinik der Ruhr Universität, Bochum, Germany.

\section{Authors' contributions}

$P B, A K G, D T, C B, M K$ and TP have been involved in the conception and design of the study. ED is responsible for the analysis of data. PB has drafted the manuscript based on the protocol and all other authors have been revising the article for important intellectual content. All authors have finally approved the version to be published.

\section{Competing interests}

Peter Bramlage, Anselm K. Gitt and Diethelm Tschöpe have received research support and honoraria for lectures from a number of pharmaceutical companies including Bristol-Myers Squibb and AstraZeneca, the sponsors of this registry. Christiane Binz, Michael Krekler and Tanja Plate are employees of the sponsors. Evelin Deeg has no potential conflict of interest to disclose.

Received: 24 July 2010 Accepted: 16 September 2010 Published: 16 September 2010

\section{References}

1. Schernthaner G: Diabetes and Cardiovascular Disease: Is intensive glucose control beneficial or deadly? Lessons from ACCORD, ADVANCE, VADT, UKPDS, PROactive, and NICE-SUGAR. Wien Med Wochenschr 2010, 160(1-2):8-19.
2. Matthaei S, Bierwirth $R$, Fritsche $A$, Gallwitz B, Haring HU, Joost HG, Kellerer M, Kloos C, Kunt T, Nauck M, Schernthaner G, Siegel E, Thienel F: Medical antihyperglycaemic treatment of type 2 diabetes mellitus: update of the evidence-based guideline of the German Diabetes Association. Exp Clin Endocrinol Diabetes 2009, 117(9):522-557.

3. UKPDS: Effect of intensive blood-glucose control with metformin on complications in overweight patients with type 2 diabetes (UKPDS 34). UK Prospective Diabetes Study (UKPDS) Group. Lancet 1998, 352(9131):854-865.

4. Gerstein HC, Miller ME, Byington RP, Goff DC Jr, Bigger JT, Buse JB, Cushman WC, Genuth S, Ismail-Beigi F, Grimm RH Jr, Probstfield JL, SimonsMorton DG, Friedewald WT: Effects of intensive glucose lowering in type 2 diabetes. N Engl J Med 2008, 358(24):2545-2559.

5. Patel A, MacMahon S, Chalmers J, Neal B, Billot L, Woodward M, Marre M, Cooper M, Glasziou P, Grobbee D, Hamet P, Harrap S, Heller S, Liu L, Mancia G, Mogensen CE, Pan C, Poulter N, Rodgers A, Williams B, Bompoint S, de Galan BE, Joshi R, Travert F: Intensive blood glucose control and vascular outcomes in patients with type 2 diabetes. $N$ Engl J Med 2008, 358(24):2560-2572.

6. Duckworth W, Abraira C, Moritz T, Reda D, Emanuele N, Reaven PD, Zieve FJ, Marks J, Davis SN, Hayward R, Warren SR, Goldman S, McCarren M, Vitek ME, Henderson WG, Huang GD: Glucose control and vascular complications in veterans with type 2 diabetes. N Engl J Med 2009, 360(2):129-139.

7. FDA: Guidance for Industry. Diabetes Mellitus - Evaluating Cardiovascular Risk in New Antidiabetic Therapies to Treat Type 2 Diabetes. 2008 [http://www.fda.gov/downloads/Drugs/

GuidanceComplianceRegulatorylnformation/Guidances/UCM071627.pdf].

8. Pfeifer MA, Halter JB, Porte D Jr: Insulin secretion in diabetes mellitus. Am J Med 1981, 70(3):579-588.

9. Avignon A, Radauceanu A, Monnier L: Nonfasting plasma glucose is a better marker of diabetic control than fasting plasma glucose in type 2 diabetes. Diabetes Care 1997, 20(12):1822-1826.

10. Bouma M, Dekker JH, de Sonnaville JJ, van der Does FE, de Vries $H$, Kriegsman DM, Kostense PJ, Heine RJ, van Eijk JT: How valid is fasting plasma glucose as a parameter of glycemic control in non-insulin-using patients with type 2 diabetes? Diabetes Care 1999, 22(6):904-907.

11. Verges $B$ : [The impact of regulation of postprandial glucose in practice]. Diabetes Metab 1999, 25(Suppl 7):22-25

12. Soonthornpun S, Rattarasarn C, Leelawattana R, Setasuban W: Postprandial plasma glucose: a good index of glycemic control in type 2 diabetic patients having near-normal fasting glucose levels. Diabetes Res Clin Pract 1999, 46(1):23-27. 
13. Feinglos MN, Thacker CH, English J, Bethel MA, Lane JD: Modification of postprandial hyperglycemia with insulin lispro improves glucose control in patients with type 2 diabetes. Diabetes Care 1997, 20(10):1539-1542.

14. Bastyr EJ, Stuart CA, Brodows RG, Schwartz S, Graf CJ, Zagar A, Robertson KE: Therapy focused on lowering postprandial glucose, not fasting glucose, may be superior for lowering HbA1c. IOEZ Study Group. Diabetes Care 2000, 23(9):1236-1241.

15. Phung OJ, Scholle JM, Talwar M, Coleman Cl: Effect of noninsulin antidiabetic drugs added to metformin therapy on glycemic control, weight gain, and hypoglycemia in type 2 diabetes. JAMA 2010, 303(14):1410-1418.

16. Dluhy RG, MCMahon GT: Intensive glycemic control in the ACCORD and ADVANCE trials. N Engl J Med 2008, 358(24):2630-2633.

17. Cox D, Gonder-Frederick L, McCall A, Kovatchev B, Clarke W: The effects of glucose fluctuation on cognitive function and QOL: the functional costs of hypoglycaemia and hyperglycaemia among adults with type 1 or type 2 diabetes. Int J Clin Pract Supp/ 2002(129):20-26.

18. Ferriss JB, Webb D, Chaturvedi N, Fuller JH, Idzior-Walus B: Weight gain is associated with improved glycaemic control but with adverse changes in plasma lipids and blood pressure isn Type 1 diabetes. Diabet Med 2006, 23(5):557-564.

19. Prato SD, LaSalle J, Matthaei S, Bailey CJ: Tailoring treatment to the individual in type 2 diabetes practical guidance from the Global Partnership for Effective Diabetes Management. Int J Clin Pract 2010, 64(3):295-304.

20. Fritsche A, Haring $\mathrm{H}$ : At last, a weight neutral insulin? Int J Obes Relat Metab Disord 2004, 28(Suppl 2):S41-46.

21. Martin S, Schramm W, Schneider B, Neeser K, Weber C, Lodwig V, Heinemann L, Scherbaum WA, Kolb H: Epidemiology of complications and total treatment costs from diagnosis of Type 2 diabetes in Germany (ROSSO 4). Exp Clin Endocrinol Diabetes 2007, 115(8):495-501.

22. Liebl A, Neiss A, Spannheimer A, Reitberger U, Wagner T, Gortz A: Kosten des Typ-2-Diabetes in Deutschland. Ergebnisse der CODE-2-Studie. Dtsch Med Wochenschr 2001, 126(20):585-589.

23. Koster I, von Ferber L, Ihle P, Schubert I, Hauner $H$ : The cost burden of diabetes mellitus: the evidence from Germany-the CoDiM study. Diabetologia 2006, 49(7):1498-1504.

24. von Ferber $\mathrm{L}$, Koster I, Hauner $\mathrm{H}$ : Medical costs of diabetic complications total costs and excess costs by age and type of treatment results of the German CoDiM Study. Exp Clin Endocrinol Diabetes 2007, 115(2):97-104.

25. Verband Forschender Arzneimittelhersteller. Prospektives Deutsches Register zur Dokumentation der ambulanten Therapie des Diabetes und der Zielwerterreichung im klinischen Alltag (DiaRegis). [http://www.vfa. de/de/arzneimittel-forschung/datenbanken-zu-arzneimitteln/nisdb/nisdetails/_303].

26. Wittchen HU, Krause $P$, Hofler M, Pfister $H$, Kupper B, Pittrow D, Bramlage $P$, Unger T, Sharma AM, Ritz E, Goke B, Lehnert H, Tschope D, Kirch W: [Aim, design and methods of the "Hypertension and diabetes screening and awareness" - (HYDRA) study]. Fortschritte der Medizin 2003, 121(Suppl 1):2-11.

27. Wittchen HU, Glaesmer H, Marz W, Stalla G, Lehnert H, Zeiher AM, Silber S Koch U, Bohler S, Pittrow D, Ruf G: Cardiovascular risk factors in primary care: methods and baseline prevalence rates-the DETECT program. Curr Med Res Opin 2005, 21(4):619-630.

28. Liebl A, Mata M, Eschwege E: Evaluation of risk factors for development of complications in Type II diabetes in Europe. Diabetologia 2002, 45(7): S23-28.

29. Liebl A, Neiss A, Spannheimer A, Reitberger U, Wieseler B, Stammer $H$, Goertz A: Complications, co-morbidity, and blood glucose control in type 2 diabetes mellitus patients in Germany-results from the CODE- 2 study. Exp Clin Endocrinol Diabetes 2002, 110(1):10-16

30. Martin S, Schneider B, Heinemann L, Lodwig V, Kurth HJ, Kolb H, Scherbaum WA: Self-monitoring of blood glucose in type 2 diabetes and long-term outcome: an epidemiological cohort study. Diabetologia 2006, 49(2):271-278.

31. Krone W, Bohm M, Wöhrmann APA, Bestehorn K: Erhebung und Verbesserung der Behandlungssituation von Patienten mit Diabetes mellitus. Das DUTY-Register. Bundesgesundheitsblatt Gesundheitsforschung Gesundheitsschutz 2004, 47(6):540-546.
32. Ott $P$, Köhler $C$, Hanefeld M: Baseline data of the Diabetes in Germany study (DIG). Prospective 4-year study on the epidemiology of type-2 diabetes in Germany. Diabetologe 2006, 2(Suppl. 1):S44-S48.

33. Hanefeld M, Koehler C, Gallo S, Benke I, Ott P: Impact of the individual components of the metabolic syndrome and their different combinations on the prevalence of atherosclerotic vascular disease in type 2 diabetes: the Diabetes in Germany (DIG) study. CardiovasC Diabetol 2007, 6:13.

34. Towae F, Bauer T, Tschöpe D, Schnell O, Standl E, Zahn R, Gitt AK: Recognition of abnormal glucose metabolism and its impact on treatment in patients with acute myocardial infarction in Germany: Results of the SWEETHEART registry. Deutsche Gesellschaft für Kardiologie Mannheim, Germany 2010.

35. Price HC, Tucker L, Griffin SJ, Holman RR: The impact of individualised cardiovascular disease (CVD) risk estimates and lifestyle advice on physical activity in individuals at high risk of CVD: a pilot $2 \times 2$ factorial understanding risk trial. Cardiovasc Diabetol 2008, 7:21.

36. Valdivielso P, Rioja J, Garcia-Arias C, Sanchez-Chaparro MA, GonzalezSantos P: Omega 3 fatty acids induce a marked reduction of apolipoprotein B48 when added to fluvastatin in patients with type 2 diabetes and mixed hyperlipidemia: a preliminary report. Cardiovasc Diabetol 2009, 8:1.

37. Moebus S, Hanisch JU, Aidelsburger P, Bramlage P, Wasem J, Jöckel K-H: Impact of four different definitions used for assessment of the prevalence of metabolic syndrome in a primary health care setting. The German Metabolic and Cardiovascular Risk Project (GEMCAS). Cardiovasc Diabetol 2007, 6(1):22.

38. Moebus S, Balijepalli C, Losch C, Gores L, von Stritzky B, Bramlage P, Wasem J, Jockel KH: Age- and sex-specific prevalence and ten-year risk for cardiovascular disease of all 16 risk factor combinations of the metabolic syndrome - A cross-sectional study. Cardiovasc Diabetol 2010, 9(1):34.

39. Wittchen HU, Krause P, Hofler M, Pfister H, Ritz E, Goke B, Lehnert $H$, Tschope D, Kirch W, Pittrow D, Sharma AM, Bramlage P, Kupper B, Unger T: [Hypertension, diabetes mellitus and comorbidity in primary care]. Fortschritte der Medizin 2003, 121(Suppl 1):19-27.

\section{doi:10.1186/1475-2840-9-53}

Cite this article as: Bramlage et al:: Diabetes treatment patterns and goal achievement in primary diabetes care (DiaRegis) - study protocol and patient characteristics at baseline. Cardiovascular Diabetology 2010 9:53.

\section{Submit your next manuscript to BioMed Central and take full advantage of:}

- Convenient online submission

- Thorough peer review

- No space constraints or color figure charges

- Immediate publication on acceptance

- Inclusion in PubMed, CAS, Scopus and Google Scholar

- Research which is freely available for redistribution

Submit your manuscript at www.biomedcentral.com/submit
C Biomed Central 